\title{
Exploration on the Teaching Reform of Medicinal Botany Based on PBL Mode and Diversification Teaching
}

\author{
Yulan Huang*, Tong Han, Guiyan Jia \\ Heilongjiang Bayi Agricultural University,Daqing, Heilongjiang, 163319,China \\ *corresponding author
}

Keywords: Medicinal botany, PBL mode, Diversification teaching

\begin{abstract}
Pharmaceutical Botany is a very important basic course for pharmacy and traditional Chinese Medicine Majors in medical colleges and universities. The content of traditional teaching model is complicated, dull, and difficult to learn and remember, which can not meet the training needs of pharmaceutical talents. The open and information-based teaching mode has brought new opportunities and challenges to the educational circles, and the curriculum mode reform of higher education is also going on. Based on the actual teaching situation, this paper analyzes the current situation of the teaching mode of Medicinal Botany and the problems existing in the teaching mode of Medicinal Botany were pointed out. Combining PBL (Problem-Based Learning) teaching mode with open information teaching resources to cultivate students' ability of exploring and acquiring knowledge, which expounds the direction of the reform of the course mode of medicinal botany, and provides a reference for the reform of the teaching mode of the course of medicinal botany.
\end{abstract}

\section{The Current Situation and Problems of Medicinal Botany}

Pharmaceutical Botany is a very important basic course for pharmacy and traditional Chinese Medicine Majors in medical colleges and universities, which includes plant morphological anatomy and systematics, being characterized by a great deal of content and knowledge. Because of teaching environment and teaching field limitation, traditional teaching of Medicinal Botany is still a point of knowledge that teachers use PPT or some pictures to impart and explain the course.

In addition, the evaluation method is not enough. Although there are usually grades and quizzes in the traditional class, the final evaluation is the main one, which leads to Students only pay attention to the memory and recitation of knowledge [1]. Under the traditional teaching mode, the teacher is the main disseminator of theoretical knowledge in the classroom teaching of Medicinal Botany, and usually introduces the contents and knowledge to the students according to the requirements of the teaching syllabus. While, students only accept the knowledge of the point of inculcation and memory passively [2]. Even if there is classroom discussion, it is mostly teacher-centered discussion and students are lack of independent or group-based interactive teaching activities, which cramming teaching has greatly limited students enthusiasm for learning and their enthusiasm for actively acquiring knowledge [3]. Therefore, in the new era, it is very 
important to seek a more effective teaching method of Medicinal Botany for cultivating innovative talents in pharmacy.

It is well known that field practice is a practical link in the teaching of Medicinal Botany. Through systematic practice teaching, students can be stimulated to learn, study and expand their cognitive range. How to integrate the theory and practice, make it internalized and consolidated, and then improve students comprehensive quality becomes very important [4]. Based on the present situation of Medicinal Botany, this paper will combine the advanced PBL teaching mode with the vast advanced network information resources, and introduce it into the teaching and practice of Medicinal Botany, which is not only to improve the teaching quality of Medicinal Botany, but also to promote the teaching of PBL and to train innovative talents of traditional Chinese medicine.

\section{Research Progress PBL Teaching Model and Diversification Teaching}

Problem-based Learning (PBL) is a Problem-Based, student-centered and teacher-oriented situational heuristic teaching model, which originated from medical education [5]. As an interdisciplinary and open teaching mode, PBL is an educational method focused on self-directed learning, small groups discussion with facilitators and working through problems to acquire knowledge, which can provide learners more opportunities for application of knowledge acquired from basic science to the working situations [6], and then can promote students continuous thinking, mold their independence and innovation ability. The effectiveness of PBL in enhancing application of knowledge, problem solving, collaborative and self-directed learning skills and high-order thinking has been documented [7-9].

With the rapid development of information technology, the development and application of modern education technology with network technology as its core have penetrated into every aspect of education and teaching [10]. In recent years, with the rapid development of wireless communication and mobile computer technology, smart terminals such as smartphones and tablet computers have entered people's lives, which are already very popular among teachers and students [11]. Network teaching is a new teaching mode with the development of computer technology and the expansion of network resources. It refers to teachers-led, student-oriented mixed teaching methods of interactive teaching activities with the use of computer network technology, network teaching resources, network teaching platform. With the development of information technology, the diversified the means of acquiring knowledge can stimulate students study interest, develop good study habits, form a broad field of vision, and improve their practical and innovative abilities [12]. Which is the inevitable development direction of the design and construction of Medicinal plant network course.

\section{The Medicinal Botany Mode of Combining PBL Teaching Mode with Open Information Teaching Resources}

There are many subjects involved in medicinal botany, the contents of which are similar, confusing and boring. Based on the present situation of Medicinal Botany, this paper will combine the advanced PBL teaching mode with the vast advanced network information resources, which pattern is divided into four parts, as shown in Figure 1.

Before the class, combining network resources with curriculum to bring up interesting and attracting topics, such as how trees talk to each other (https://www.ted.com/talks/suzanne simard how trees talk to each other?referrer= playlist-the secret lives of_plants). And then morphological structure and function of root will be put forward and the students may understand the objective of teaching task. The question can stimulate the interest of student enormously, which also is proposing question in PBL teaching mode. 
After the question is put forward, the students begin to discuss the question in groups. According to the requirement of the basic task, the students are divided many groups and use a variety of network resources, such as full text flora of the People's Republic of China, Chinese plant species information data, Plant image database of China (http://www.plantphoto.cn/), Chinese virtual herbarium and some digital library of university of traditional chinese medicine etc. According to the resources of the network, the students start to analyze and discuss the problems, which also is analyzing question in PBL teaching mode.

Students in each group can refer to the full-text databases of Chinese and foreign electronic periodicals (Weipu, CNKI, Pubmed, Elsevier, etc.) to summary. After that, the group selects a representative to report results to the classmates and the teacher. According to the report, and then the teacher and the student work together to summarize the solution, which also is resolving question in PBL teaching mode.

At the same time, it can take many network forms to evaluate the teaching effect. Teachers can also clarify, correct and sum up some key knowledge points and common problems in the process of students completing tasks, so as to avoid similar problems in the future and make students really grasp the ability and methods of solving and analyzing problems.

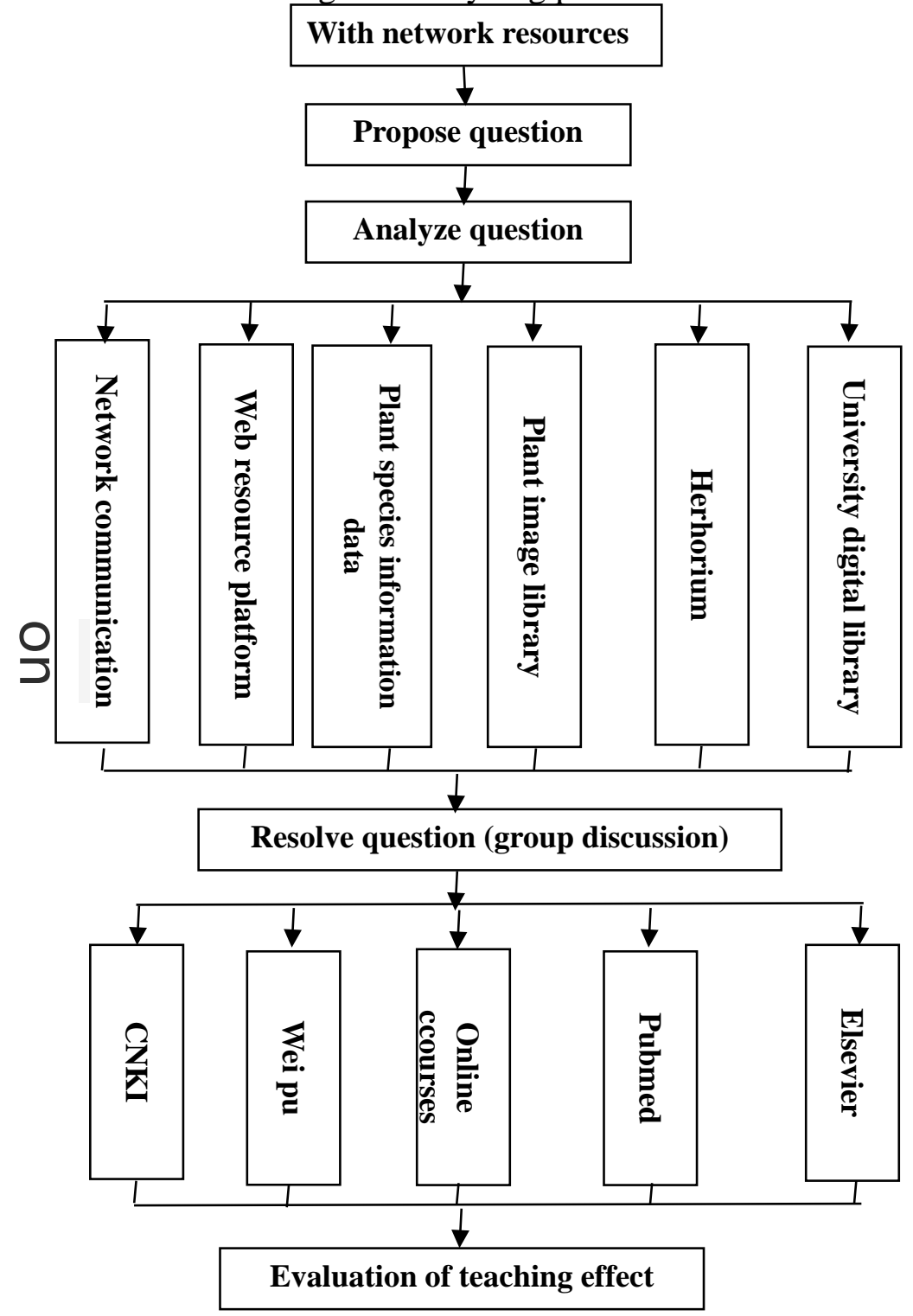


Figure 1: Implementation process of combining PBL teaching mode with open information teaching resources

\section{Discussion}

In process of implementing the teaching model of combining PBL teaching mode with open information teaching resources, It is difficult for teachers to control the time and energy invested by students in advance self-study textbooks, teaching videos and teaching materials, leading to the poor quality of pre-class learning .How to improve the enthusiasm and initiative of the students in the course of medicinal botany is the key to guarantee the effect of the classroom teaching. Interest is the best teacher, therefore, to enhance students interest in medicinal botany is the premise of ensuring student self-study. At this time, teachers should explore more high-quality network learning resources and more interesting teaching video, which can enhance their awareness and ability of self-discovery and utilization of open educational resources, and finally improve students autonomous learning ability.

On the other hand, teachers are required to have high quality, carefully design interesting and attractive problems, effectively grasp the rhythm of discussion in class, and can deeply systematic analyze and discuss proposed problems. In addition to, teachers are required to have solid and extensive subject knowledge and must also be familiar with the development of open network information resources in medicinal botany subject, and then can timely and effective communicate to students.

\section{Conclusion}

This research takes modern education thought as the forerunner, according to the undergraduate pharmacy specialized talented person training goal, combining PBL teaching mode with open information teaching resources and trying to apply it in medicinal botany teaching activities systematically. The teaching model mainly consisted of four phases, separately being proposing question, analyzing question, resolving question and evaluation of teaching effect. At the same time, the application of open network information resources has been throughout. This web-based PBL learning model not only can learn to use the vast network of resources to analyze and solve problems but also can broaden the students' thoughts, broaden their horizons, enrich their knowledge, make them enthusiastic to learn medicinal botany and then realize the goal of cultivating pharmaceutical professionals. The article expounds the direction of the reform of the course mode of medicinal botany, and provides a reference for the reform of the teaching mode of the course of medicinal botany.

\section{References}

[1] Guo, Q.M., Song, Y.M., Wan, P., Sun, Z.Y., Bao, H.Y., Gao, D.M. (2017) Research and Exploration on Reform of Blended Teaching Model of Pharmaceutical Botany. Chinese Journal of Experimental Traditional Medical Formulae, 23(16), 4-7.

[2] Ryback, D., Sanders, J.J. (1980) Humanistic versus Traditional Teaching Styles and Student Satisfaction. J Humanist Psychol, 20(1), 87-90.

[3] Shu, G.W. (2017) The discussion on semi-open teaching mode of Medicinal Botany. Journal of Biology, 34(5), 124-126.

[4] Cheng, H.Y., Ou L. (2010) The reform and practice of field teaching practice of Medicinal Botany. Report on traditional Chinese medicine, 16(9), 130-131. 
[5] Shen, J., Xu, Y.H., Shao, S.G. et al. (2010) Application of PBL teaching model in the teaching of Medicinal Botany. Anhui Agricultural Science, 38(25), 14144-14145.

[6] Galvao, T.F., Silva, M.T., Neiva, C.S., Ribeiro, L.M., Pereira, M.G. (2014) Problem- based learning in pharmaceutical education: A systematic review and meta-analysis. Scientific World Journal, 2014, 578382.

[7] Khatiban, M., Sangestani, G. (2014) The effects of using problem-based learning in the clinical nursing education on the students' outcomes in Iran: A quasi experimental study. Nursing Education in Practice 14(6), 698-703.

[8] Mansor, A.N., Abdullah, N.O., Wahab, J.A., Rasul, M.S., Nor, M.Y.M., Nor, N.M. et al. (2015) Managing problem-based learning: Challenges and solutions for educational practice. Asian Social Science, 1(4), 259-268.

[9] Yang, J.H., Yang, B. (2013) Nursing students experiences with facilitator in problem based. Asian Nursing Research, 7, 198-204.

[10] Wang, G.Z., Yan, Z.Y., Wan D.G. (2015) Online medicinal botany course construction based on network environments. Pharmacy and Clinics of Chinese Materia Medica, 6(4), 34-36.

[11] Zhu, Y., Wang, X.F., Li, P., Wang, Q., Tang, H. (2016) Practice and exploration of the application of smart phone in the experimental teaching of Medicinal Botany. Experiments and pracise, 17(34), 90-91.

[12] Chen, L., Wan, D.G., Yan, Z.Y., Wang, G.Z. (2017) Application of Problem-Based Learning teaching model based on computer network platform in Pharmaceutical Botany teaching process. Pharmacy and Clinics of Chinese Materia Medica, 8(5), 47-49. 